\title{
Numerical and experimental study of concrete I-beam subjected to bending test with cyclic load
}

\author{
Paula de Oliveira Ribeiroa* (D), Gustavo de Miranda Saleme Gidrão ${ }^{a}$ (D), Luiz Vicente Vareda ${ }^{a}$ (D), \\ Ricardo Carrazedo ${ }^{a}$ (D), Maximiliano Malite ${ }^{\text {(iD }}$
}

a Departamento de Engenharia de Estruturas, Escola de Engenharia de São Carlos, Universidade de São Paulo. Av. Trabalhador São-carlense 400, São Carlos, SP, Brasil. E-mail: paula_ribeiro@usp.br, gustavo.gidrao@gmail.com, Ivvareda@sc.usp.br, carrazedo@sc.usp.br, mamalite@sc.usp.br.

* Corresponding author

http://dx.doi.org/10.1590/1679-78255880

\begin{abstract}
This paper provides guidelines for cyclic loading bending test simulation and modal analysis of a reinforced concrete I-beam. For this purpose, experimental and numerical cyclic bending test were performed. In the experimental study, the natural frequencies of the structure in the intact and damaged states were measured. The simulation of the cyclic bending test was done with Concrete Damaged Plasticity model (CDP), implemented in Abaqus finite element software. Based on the experimental results, different constitutive models for concrete were evaluated. In order to evaluate the dynamic behavior of the structure in the numerical model, the automatic calibration of the finite element model by Genetic Algorithm (GA) was used. With the calibrated numerical model, methodologies for estimating the overall damage of the structure based on its dynamic properties were proposed. The results confirm that the well-designed numerical model is able to efficiently represent the cyclic loading bending test. In addition, the proposed global damage estimates demonstrate the coherence between numerical and experimental models.
\end{abstract}

\section{Keywords}

I-Beam, modal analysis, finite element model, cyclic load.

\section{Graphical Abstract}
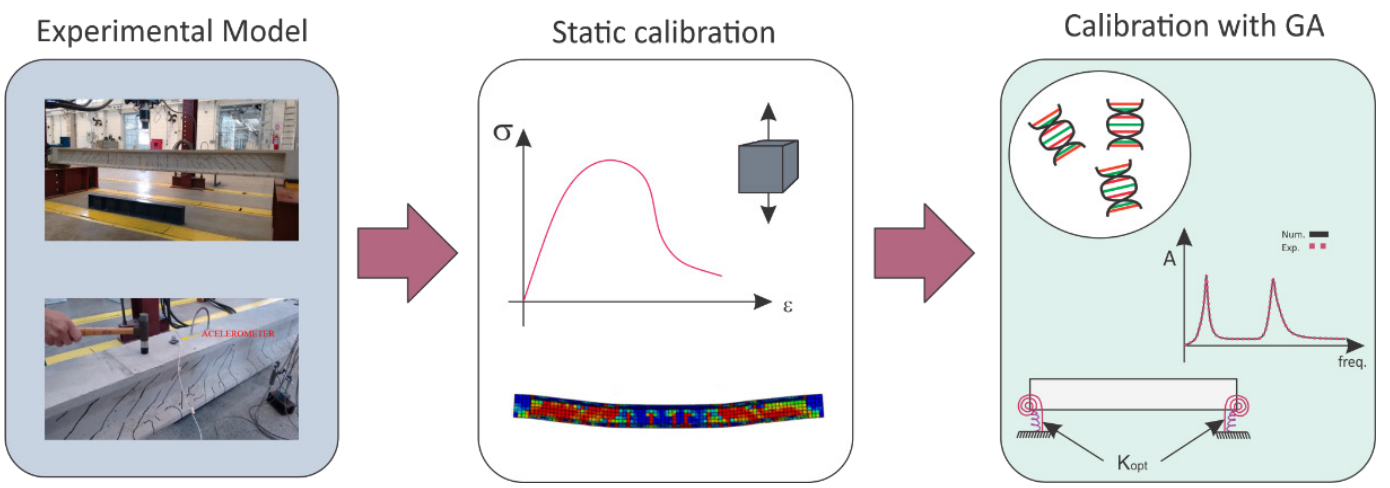


\section{INTRODUCTION}

Physical nonlinearity of concrete can be treated with different models, namely: nonlinear elastic, elastoplastic and elastoplastic damage models. The nonlinear elastic and elastoplastic models satisfactorily simulate the ascending branch of the stress-strain curve of concrete under monotonic loading. However, when considering cyclic loading, these are not able to accurately predict the behavior of the material. In this sense, we observe simultaneously the accumulation of plastic strain and degradation of the elasticity modulus. An alternative to overcome this problem is to use for example elastoplastic damage models, which presents the advantage of computing both the plastic strain accumulation and reducing the elasticity modulus due to damage of the material, which are more accurate and realistic (Genikomsou and Polak, 2015; Jankowiak and Lodygowski, 2005).

In this sense, the Concrete Damaged Plasticity (CDP), implemented in Abaqus commercial finite element software (Abaqus, 2014), is a model able to compute both material damage and the accumulation of plastic strain. This model is remarkable because it has been successfully applied to predict the behavior of concrete structures in various situations of geometry, material and loading conditions (Chen and Graybeal, 2011; Genikomsou and Polak, 2015; Graybeal, 2008; Singh et al., 2017; Tao and Chen, 2014). The study by Genikomsou and Polak (2015) is notable, in which nonlinear finite element analysis was performed on reinforced concrete pillar connections under static and pseudo-dynamic loads, investigating the failure modes in terms of final load and cracking patterns. Tao and Chen (2014) presented a simple and robust finite element (FE) model to simulate the bonding behavior between conventional concrete and fiber reinforced polymer (PRF), characterizing the take-off process for the single shear test. The works of Chen and Graybeal (2011), Graybeal (2008) and Singh et al. (2017) stand out for simulating the flexural behavior of UHPFRC beams using concrete damaged plasticity.

It should be noted that all the works described above presented great consistency between the experimental and numerical results, indicating the robustness of the CDP for the simulation of concrete structural elements.

\section{CONCRETE DAMAGED PLASTICITY MODEL (CDP)}

The Concrete Damaged Plasticity (CDP) is a model already implemented in ABAQUS CAE ${ }^{\circledR}$ and often applied to model the non-linear physical behavior of concrete structures. It describes the behavior of concrete in a predetermined stress state, coupling the concepts of plasticity and damage (Jankowiak and Lodygowski, 2005; Johnson, 2006; Wahalathantri et al., 2011). The model admits two failure mechanisms: (i) tension rupture and (ii) compression crushing. Micro-cracks and cracks are represented macroscopically with a softening stress-strain response. When the concrete is unloaded from any point on the strain softening branch of the stress-strain curves, the unloading response is weakened, the elastic stiffness of the material is degraded, and a plastic strain is observed. The degradation of the elastic stiffness is characterized by two damage variables, $d_{t}$ (damage due to tension) and $d_{c}$ (damage due to compression). In this modeling approach, the concrete behavior is considered independently of the rebar. Figure 1 presents the tensile (Fig. 1.a) and compressive (Fig. 1.b) uniaxial responses of concrete, in CDP. 


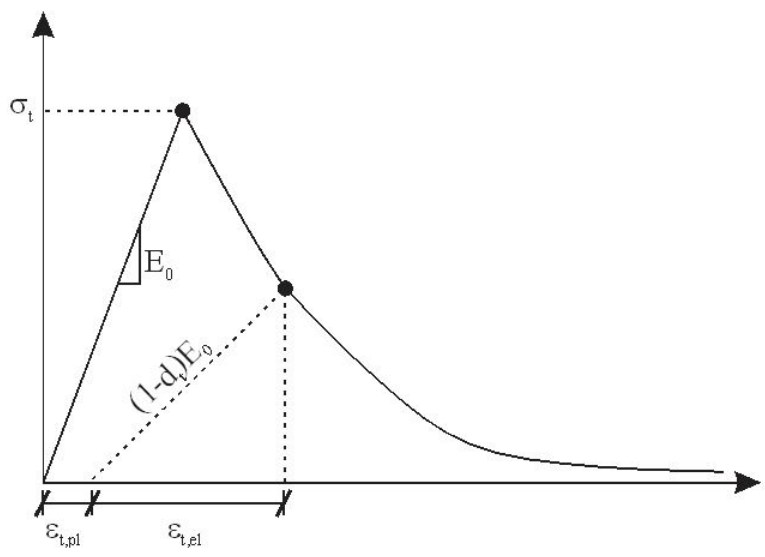

(a)

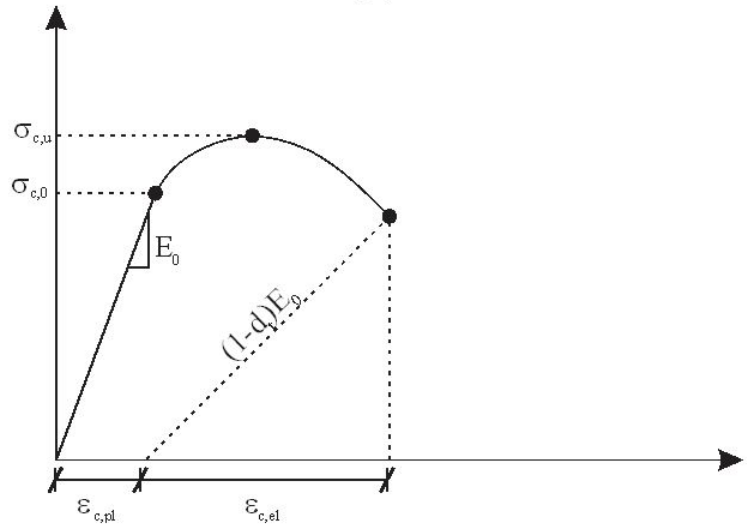

(b)

Figure 1 Uniaxial stress-strain response of concrete, in CDP

Where: $\varepsilon_{\mathrm{t}, \mathrm{pl}}$ and $\varepsilon_{\mathrm{c}, \mathrm{pl}}$ are the plastic strains in tensile and compression; $\varepsilon_{\mathrm{t}, \mathrm{el}}$ and $\varepsilon_{\mathrm{c}, \mathrm{el}}$ are the elastic strains in tension and compression; $E_{0}$ is the initial elasticity modulus; $d$ is the damage index; $\sigma_{t}$ is the maximum tensile stress and its respective elasticity limit; $\sigma_{c, 0}$ is the limit of elasticity for uniaxial compression; $\sigma_{c, u}$ is the maximum compressive stress.

A constitutive law can be established to correlate Cauchy tensor of stress $(\sigma)$ to the tensors of strains $\left(\varepsilon\right.$ e $\left.\varepsilon_{\mathrm{pl}}\right)$, according to Eq. 1:

$\sigma=(1-d) E_{0}:\left(\varepsilon-\varepsilon_{p l}\right)=E_{e l}:\left(\varepsilon-\varepsilon_{p l}\right)$

Where, $d$ is the damage index ( $d_{t}$ or $\left.d_{c}\right)$; $\varepsilon$ is the tensor of total strains; $\varepsilon_{p l}$ is the tensor of plastic strains; $E_{e l}$ is the damaged elastic stiffness, given by: $\mathrm{E}_{\mathrm{el}}=(1-\mathrm{d}) \mathrm{E}_{0} ;\left(\varepsilon-\varepsilon_{\mathrm{pl}}\right)$ are defined as the inelastic strain. All analysis performed in this paper utilized the CDP model to represent the nonlinear behavior of concrete.

The CDP yielding function was developed by Lee and Fenves (1998) and Lubliner et al. (1989), according to Eq. 2:

$$
(\bar{\sigma}, \kappa)=\frac{1}{1-\alpha}\left[\bar{q}-3 \alpha \bar{p}+\beta\left(\tilde{\varepsilon}^{p}\right)\left\langle\hat{\bar{\sigma}}_{\max }\right\rangle-\gamma\left\langle-\hat{\bar{\sigma}}_{\max }\right\rangle\right]-\bar{\sigma}_{c}\left(\tilde{\varepsilon}_{c}^{p}\right)
$$

Where: $\bar{q}=\sqrt{3 / 2 \bar{S}: \bar{S}}$ is the Mises equivalent effective stress; $\bar{p}=-1 / 3 \bar{\sigma}: I$ is the effective hydrostatic stress; and $\bar{\sigma}_{c}$ is the initial yield compressive stress. The stress $\bar{\sigma}_{\max }$ is the algebraically largest eigenvalue of the effective stress tensor and $\kappa$ represents the damage variables that are different for tension and compression.

The dimensionless constants $\alpha, \beta$ and $\gamma$ are obtained from experimental results. Parameters $\beta$ and $\gamma$ are represented in the yielding function with respect to the algebraically maximum eigenvalue signal by the Macaulay brackets $\langle x\rangle=(|x|+x) / 2$.

Where: 


$$
\begin{aligned}
& \left\langle\hat{\bar{\sigma}}_{\text {max }}\right\rangle=\left\{\begin{array}{l}
\hat{\bar{\sigma}}_{\text {max }} \text { if } \hat{\bar{\sigma}}_{\text {max }} \geq 0, \beta \text { is introduced } \\
0 \text { if } \hat{\bar{\sigma}}_{\text {max }} \leq 0
\end{array}\right. \\
& \left\langle-\hat{\bar{\sigma}}_{\max }\right\rangle=\left\{\begin{array}{l}
-\hat{\bar{\sigma}}_{\max } \text { if } \hat{\bar{\sigma}}_{\text {max }} \leq 0, \gamma \text { is introduced } \\
0 \text { if } \hat{\bar{\sigma}}_{\text {max }} \geq 0
\end{array}\right.
\end{aligned}
$$

The parameter $\beta$ is based on the hardening/softening evolution law for tension and compression (Lee and Fenves, 1998), according to Eq. 4.

$$
\beta\left(\tilde{\varepsilon}_{c}^{p}\right)=(1-\alpha) \frac{f_{c 0}\left(\tilde{\varepsilon}_{c}^{p}\right)}{f_{t}\left(\tilde{\varepsilon}_{c}^{p}\right)}-(1+\alpha)
$$

Equation 5 presents the parameter $\alpha$, which is obtained from the relation between initial yield compressive stress $f_{c 0}$ and biaxial initial yield compressive stress $f_{b c 0}$.

$\alpha=\frac{f_{b c 0} / f_{c 0}-1}{2 f_{b c 0} / f_{c 0}-1}$

Parameter $\gamma$ is obtained from the Kc constant, which governs the spacing between compression and tension meridians and the section shape of yielding surface on deviatoric plane, Eq. 6. The lower and upper limits of Kc are 0.5 e 1.

$$
\gamma=\frac{3\left(1-K_{c}\right)}{2 K_{c}-1}
$$

Prandl-Reuss flow rule gives the relation between the direction of plastic strain and the plastic strain rate, Eq. 7:

$$
\varepsilon_{i j}^{p}=\lambda \frac{\partial G}{\partial \sigma_{i j}}
$$

Where $\lambda$ is the plastic multiplier obtained from the consistency condition and $\mathrm{G}$ is a Drucker-Prager type function adopted as plastic potential function which governs the flow rule, equation 8 .

$$
G=\sqrt{\left(m f_{t} t g \varphi\right)^{2}+q^{2}}-p \operatorname{tg} \varphi
$$

The value of $\mathrm{f}_{\mathrm{t}}$ is the uniaxial tensile strength of concrete. The plastic potential function is commonly presented in $\mathrm{p}$-q plane, where $\mathrm{p}$ is the hydrostatic stress and $\mathrm{q}$ is the Mises equivalent stress. Eccentricity $m$ and dilation angle $\varphi$ are important parameters that characterize the plastic potential curve. Table 1 shows values usually adopted for CDP parameters.

Table 1 Values usually adopted for CDP parameters

\begin{tabular}{ccc}
\hline Parameter & Range & Bibliography \\
\hline$\varphi$ & $300-40$ - Jankowiak and Lodygowski, 2005; Michal and Andrzej, 2015; Kmiecik and Kaminski, 2011; \\
Pavlović et al., 2013.
\end{tabular}




\section{OBJECTIVES}

Given the context and numerical formulation properly presented, this paper advances to demonstrate a numericalexperimental study of a reinforced concrete I-beam, subjected to cyclic loading, using the constitutive model for Concrete Damaged Plasticity. The objectives of this investigation can be listed below:

- Demonstrate the methodology for calibration of the cyclic loading bending test of a concrete beam, presenting in detail the numerical modeling procedures and discussing the difficulties encountered for this type of simulation;

- Inferring which damage law is the most suitable for flexural failure mode;

- Correlate the tensile damage obtained by the numerical model to the experimental cracking pattern, and consequently characterize the failure mode presented by the beam;

- Estimate global damage through the natural frequency attainment methodology.

\section{EXPERIMENTAL MODEL}

\subsection{Static test}

The I-beam had a total length of $400 \mathrm{~cm}$, with a free span of $380 \mathrm{~cm}$, according to Figure 2. The beam was fixed on neoprene supports. The bottom longitudinal reinforcement was composed by three bars of $12.5 \mathrm{~mm}$ diameter, while three longitudinal bars of $6.3 \mathrm{~mm}$ diameter were positioned in the top region of the beam. Transverse bars of diameter of $6.3 \mathrm{~mm}$ were spaced $15 \mathrm{~cm}$ apart, following Figure 3 . The concrete clear cover used was $1.5 \mathrm{~cm}$.

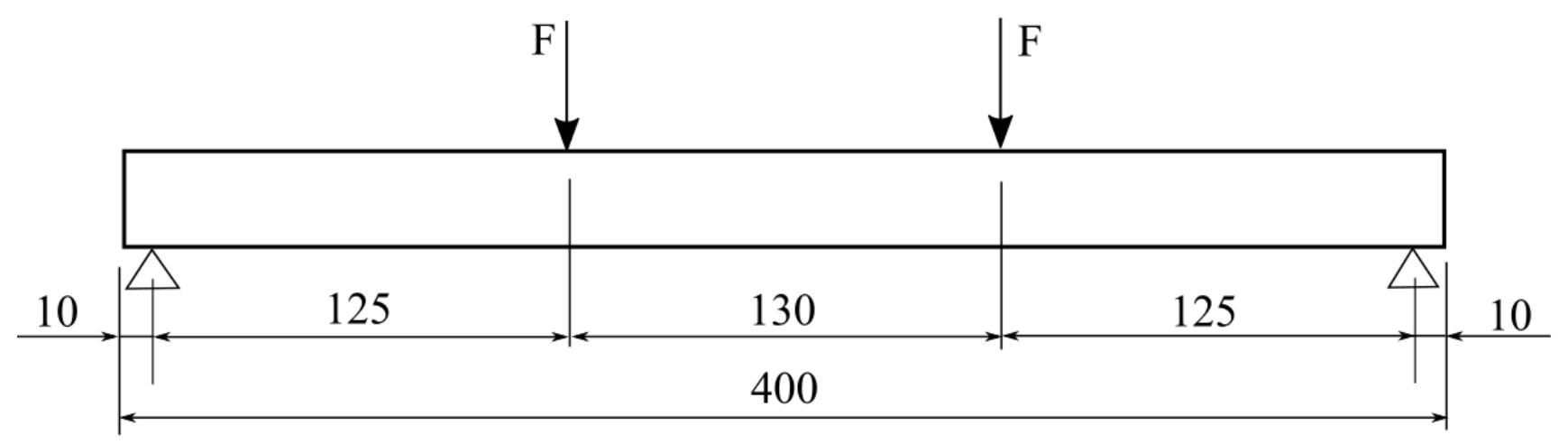

Figure 2 Schematic representation of I beam. 

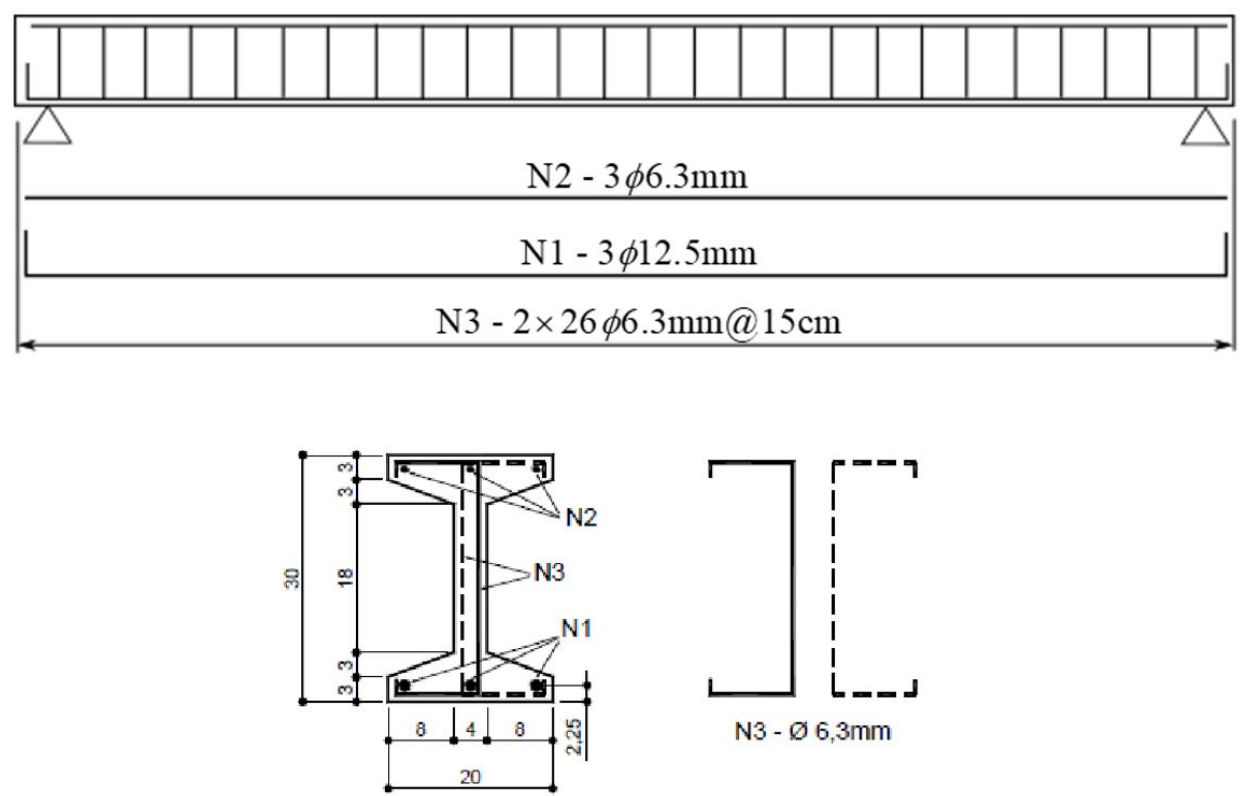

Figure 3 Representation of longidtudinal and transverse bars (all dimensions are in $\mathrm{cm}$ )

The static test consisted of applying $50 \%$ of the rupture load, unloading and reapplying the load until the ultimate force, as shown in Figure 4.

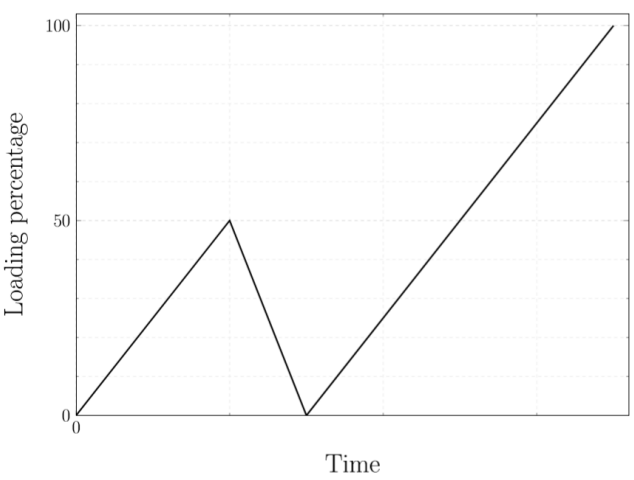

Figure 4 Cyclic test procedure.

In the static test, an auxiliary metallic beam was used to divide the concentrated load, according to Figure 5 . The cyclic test was carried out using a servo-hydraulic actuator (MTS, model 244.41), with capacity of $500 \mathrm{kN}$ and amplitude of $150 \mathrm{~mm}$. The displacement control was used. Electric extensometers were fixed on longitudinal and transverse bars (KFG-5-120-C1-11) and concrete (KFG-10-120-C1-11, see Figure 6). The central displacement of the beam was measured using a linear variable differential transformer (LVDT), with amplitude of $100 \mathrm{~mm}$ and $50 \mathrm{~mm}$, according to Figure 5. At the supports, an inclinometer sensor was used, model AccuStar IP-66, with measurement up to 45 degrees (see Figure 5). The experimental data of load, strains and displacements were recorded in a digital acquisition system (Vishay-measurements group, model System 5000).

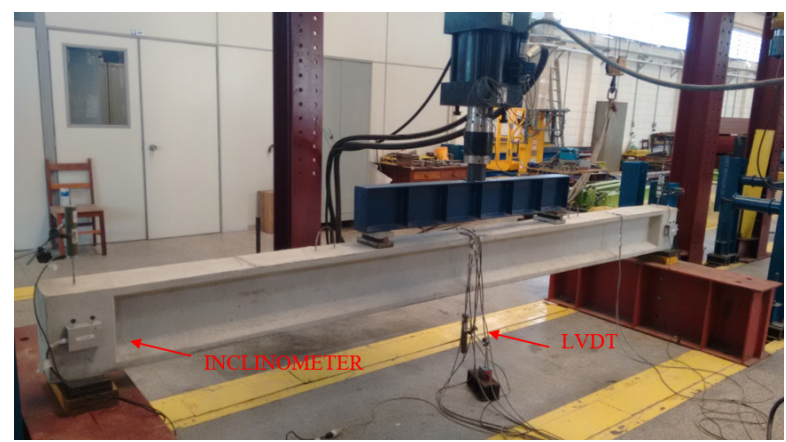

Figure 5 Static test setup 


\subsection{Dynamic test}

A dynamic test was accomplished at three predefined stages: (1) Before the mechanical static test, where the I-beam was at full integrity; (2) at $50 \%$ of the predicted rupture load value; and (3) final. At the end of each load step, the acceleration over time was measured through a piezoelectric accelerometer (Endevco, Instrom 7254-100). An impact excitation was carried out using an instrumented hammer (Endeveco 2303, range of $5000 \mathrm{lbf}$ ). The data was recorded using a dynamic and digital acquisition system (Data Physics, model SignalCalc ACE). The excitation points were predefined in the center of the span.

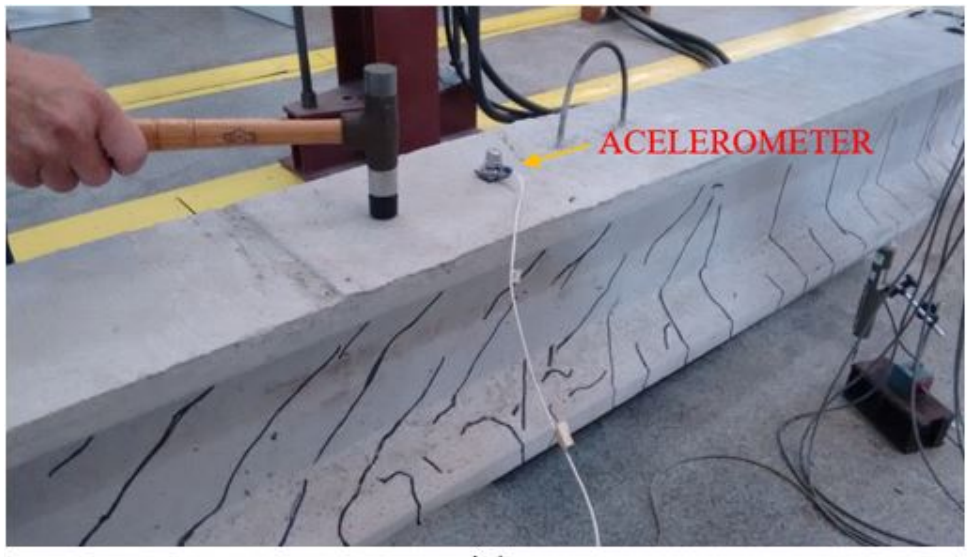

(a)

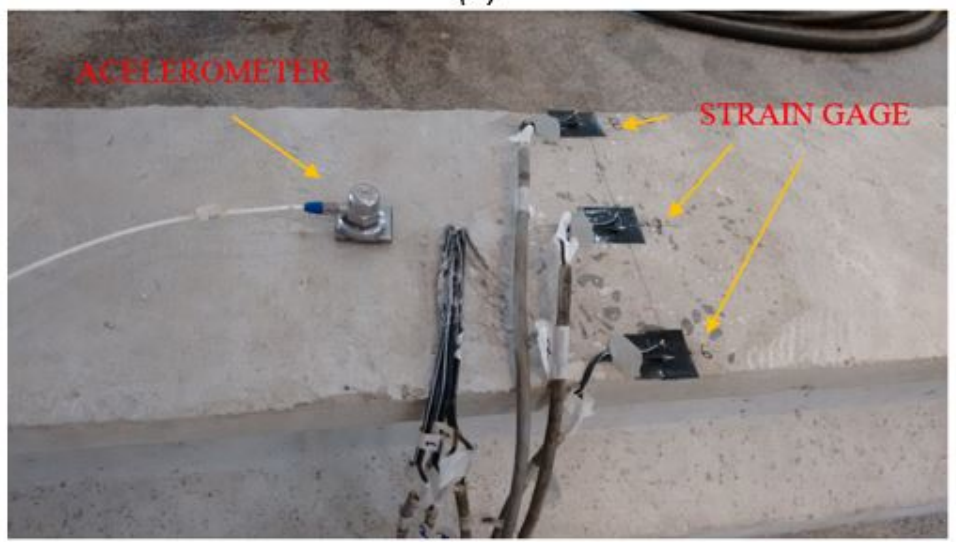

(b)

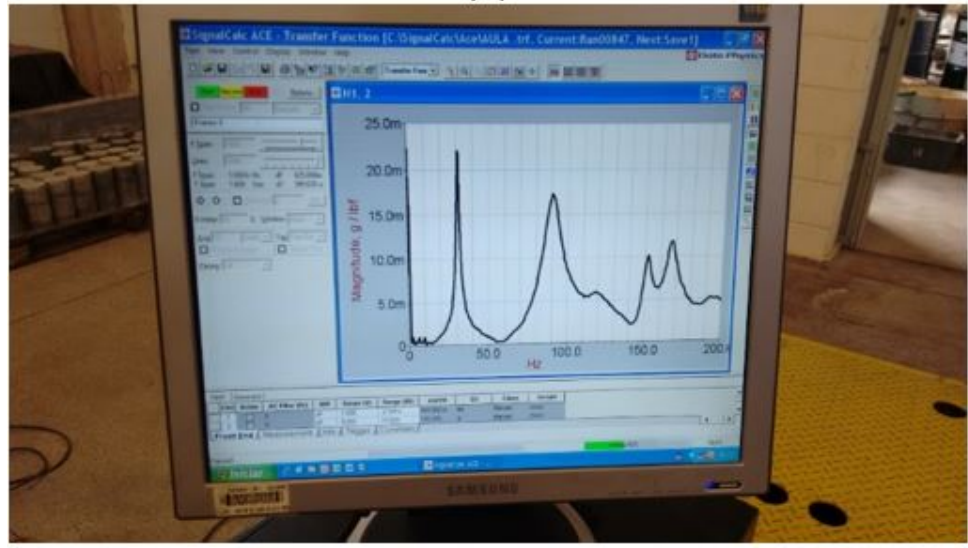

(c)

Figure 6 Dynamic test setup: (a) Impact Hammer; (b) Detail of acelerometers and (c) Record digital system

\subsection{Technological control}

The mix material proportions (in mass) were 1:2.7:3.7:0.6 (cement, sand, gravel and water), with cement weighing $300 \mathrm{~kg} / \mathrm{m}^{3}$ and slump measure of $12 \mathrm{~cm}$. Three cylindrical samples of $200 \mathrm{~mm}$ by $100 \mathrm{~mm}$ were used to determine the technological control of the material. These samples were subject to a compressive monotonic load, with stress-strain 
curves presented in Figure 7. Furthermore, Brazilian tests were carried out to obtain the diametral tensile strength of this concrete mixture. The average mechanical properties are presented according to Table 2. Three steel bars were subjected to direct tensile test, and these tests determined the average yield stress of $535 \mathrm{MPa}$ and average rupture stress of $647.33 \mathrm{MPa}$. Figure 8 presents the stress-strain curve respective to the steel bars.

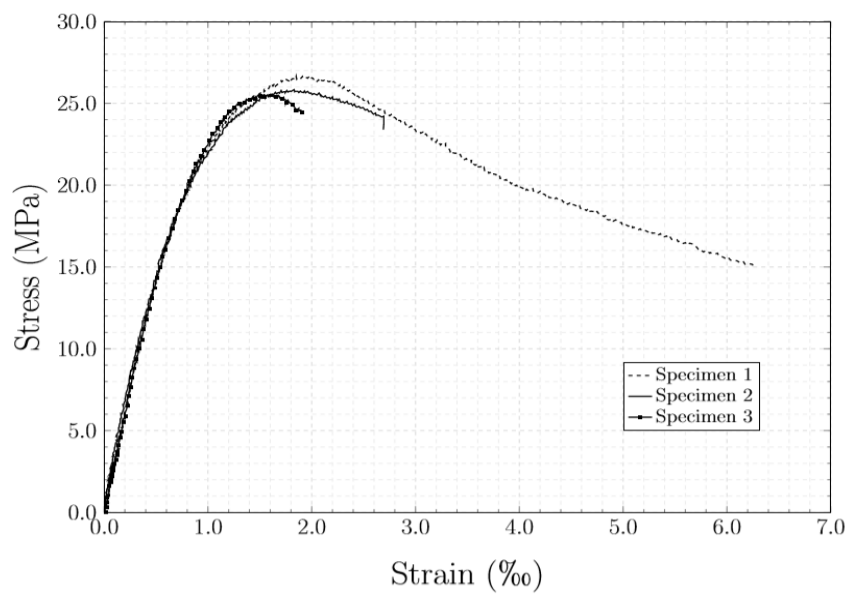

Figure 7 Concrete stress-strain curve

Table 2 Mechanical properties of the concrete mixture

\begin{tabular}{cc}
\hline Propertie & $\begin{array}{c}\text { Average } \\
\text { (MPa) }\end{array}$ \\
\hline Compressive Strength & 26.06 \\
Tensile Strength & 2.303 \\
Flexural strength & 3.61 \\
\hline
\end{tabular}

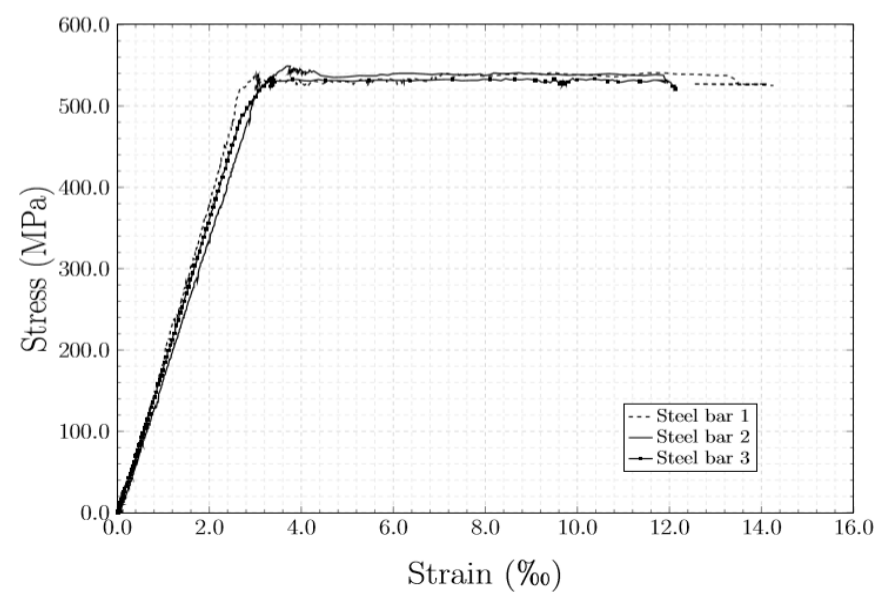

Figure 8 Steel stress-strain curve

\section{NUMERICAL MODEL}

The static test performed was simulated via the finite element method (FEM) using the Abaqus software. Similar to the experimental model, the displacement was applied until 50\% of rupture load, and then, the loading was removed and again reapplied until the ultimate force. A nonlinear numerical analysis was performed by the complete Newton method with a maximum number of increments equal to $10^{8}$, an initial increment equal to 0.001 and a maximum increment equal to 0.01. A concrete physical nonlinearity was considered through the Concrete Damaged Plasticity model (CDP) implemented in Abaqus. 


\subsection{Compressive behavior}

In this paper, the stress-strain curve proposed by Carreira and Chu (1985) was used, according to equations (9), (10), (11) and (12). Figure 9 presents the stress-strain curve, where the experimental value of $\mathrm{f}_{\mathrm{cm}}=26 \mathrm{MPa}$ was obtained. This constitutive law was used as input in the CDP model.

$\frac{\sigma}{\sigma_{0}}=\frac{\beta \cdot \varepsilon / \varepsilon_{0}}{\beta-1+\left(\varepsilon / \varepsilon_{0}\right)^{\beta}}$,

$\beta=\frac{1}{1-\frac{\sigma_{0}}{\varepsilon_{0} \cdot E_{c}}} ;$

$E_{c}=25800 \cdot\left(\frac{f_{c m}}{10}\right)^{1 / 3}$

$\varepsilon_{0}=0,7 \cdot \frac{f_{c m}^{0.31}}{1000}$

Where: $\sigma_{0}$ is the maximum compressive stress; $\varepsilon_{0}$ is the strain related to $\sigma_{0}$; $E_{c}$ is the elasticity modulus; and $f_{c m}$ is the compressive strength.

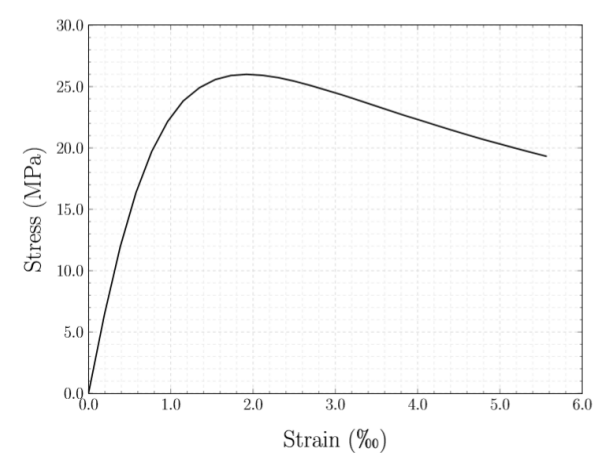

Figure 9 Compression stress-strain curve

\subsection{Tensile behavior}

The tensile stress-strain curve was obtained according to the work by Genikomsou and Polak (2015), following Figure 10. The value of fracture energy $\left(\mathrm{G}_{\mathrm{f}}\right)$ was computed according to Eq. 13, contained in item 5.5.5.2 of Model Code 2010 (COMITÉ EURO-INTERNACIONAL DU BÉTON, 2010). Figure 11 presents the tensile stress-strain law of concrete with $\mathrm{f}_{\mathrm{cm}}=26 \mathrm{MPa}, \mathrm{f}_{\mathrm{t}}=1.65 \mathrm{MPa}$ and a finite element of $50 \mathrm{~mm}$, used as inputs in the concrete damaged plasticity model in Abaqus.
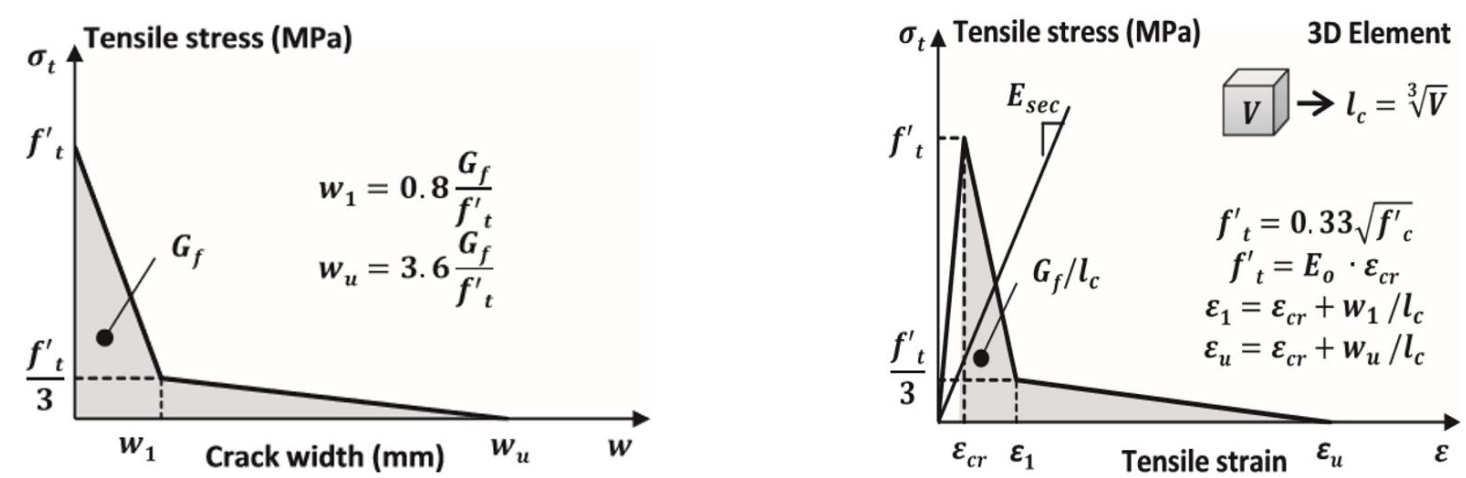

Figure 10 Analytical tensile stress-strain 


$$
G_{f}=73 \cdot\left(f_{c m}\right)^{0.18}
$$

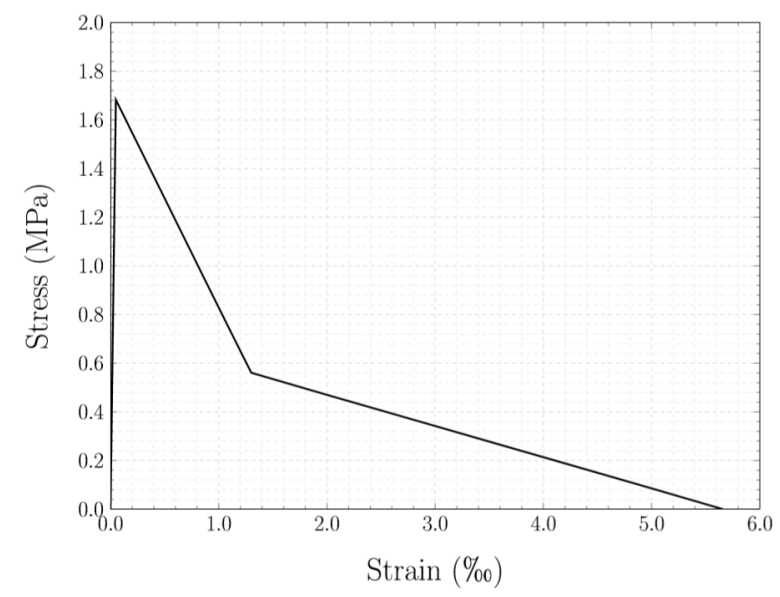

Figure 11 Tensile stress-strain curve

\subsection{Damage laws}

The law employed to simulate evolution of compressive damage is according to Eq. 14 and Figure 12. It is necessary to highlight that damage is activated after the maximum stress is reached (i.e., $\varepsilon_{\mathrm{c} 1} \leq \varepsilon_{\mathrm{c}}$ ).

$d_{c}=1-\frac{\sigma}{\sigma_{0}} \Rightarrow \varepsilon_{c 1} \leq \varepsilon_{c}$

Where: $\sigma_{0}$ is the peak stress; and $\sigma$ is the post-peak stress.

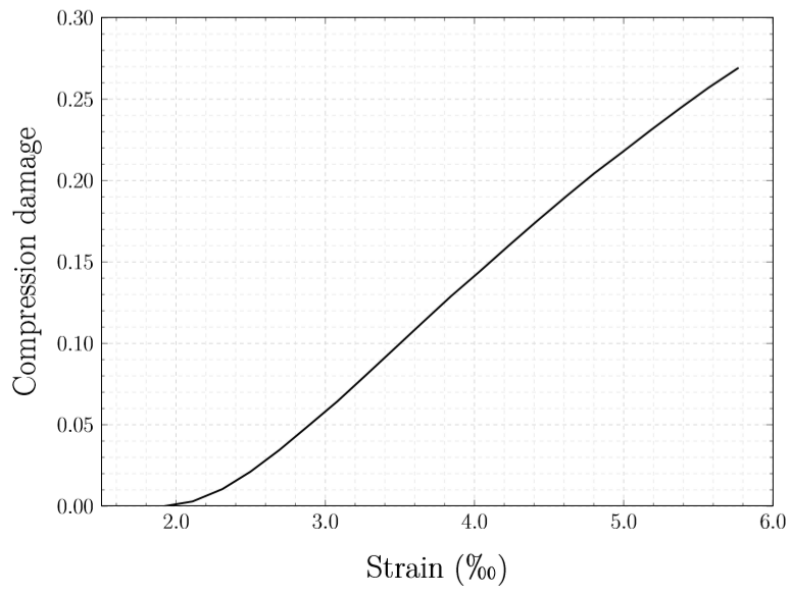

Figure 12 Compressive damage law

In the tensile damage case, the purpose of this paper is the evaluation of three damage laws: (i) A simplified law (Singh et al., 2017; Sümer and Aktaş, 2015) given by Eq. 15, (ii) an exponential law based on study of Krahl, Carrazedo and El Debs (2018) (Eq. 16) and (iii) the Birtel and Mark's law (Eq. 17):

$d_{t}=1-\frac{\sigma_{t}}{\sigma_{0 t}} \Rightarrow \varepsilon_{t 1} \leq \varepsilon_{t}$

$d_{t}(\varepsilon)=y_{0}+A_{1}\left(1-e^{-\varepsilon / t 1}\right)+A_{2}\left(1-e^{-\varepsilon / t 2}\right)$ 


$$
d_{t}=1-\frac{\sigma_{t} E_{c}^{-1}}{\varepsilon_{t}^{p l}\left(1 / b_{t}-1\right)+\sigma_{t} E_{c}^{-1}}
$$

Where: $\sigma_{t}$ is the post-peak stress; $\sigma_{0 t}$ is the peak stress; $A_{1}, A_{2}, y_{0}, t_{1}$ and $t_{2}$ are empirical coefficients; $\varepsilon$ is the total strain; $\varepsilon_{\mathrm{pl}}$ is the plastic strain; $E_{c}$ is the elasticity modulus; and $b_{t}$ is an empirical coefficient between 0 and 1 , which the initial prediction is 0.1 in the tensile case.

It is necessary to highlight that the study of Krahl, Carrazedo and El Debs (2018) was focused on the evaluation of the behavior of Ultra High Performance Fiber-Reinforced Concrete (UHPFRC); therefore, adaptations in the coefficients are necessary. Table 3 shows the parameters adopted.

Table 3 Parameters adopted for the damage evolution law proposed by Krahl, Carrazedo and El Debs (2018)

\begin{tabular}{ccc}
\hline Parameter & Value adopted \\
\hline $\mathrm{Y}_{0}$ & -0.22146 \\
$\mathrm{~A}_{1}$ & 0.95 \\
$\mathrm{~A}_{2}$ & 0.3286 \\
$\mathrm{~T}_{1}$ & $3.66896 \mathrm{E}-4$ \\
$\mathrm{~T}_{2}$ & 0.00951 \\
\hline
\end{tabular}

Figure 13 illustrates the damage evolution laws. Note that the evolution of damage increases most significantly in the Birtel and Mark (2006) model, followed by the adapted model by Krahl, Carrazedo and El Debs (2018), and the simplified damage model increases very slowly.

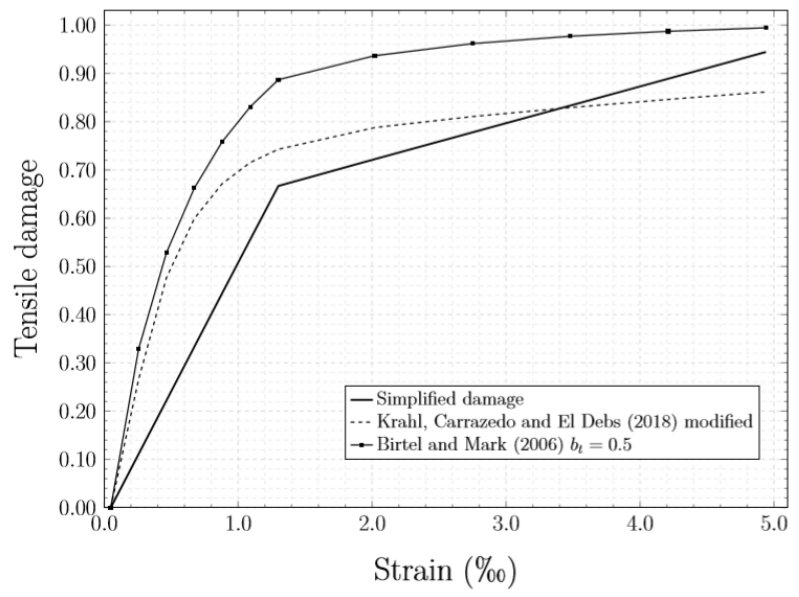

Figure 13 Tensile damage law

\subsection{Numerical modeling}

The geometries of the beam, steel bars and the actuator were made separately and through the Abaqus interaction module were made as interactions between parts. The pistons were simulated with the rigid element R3D4 and were used by the loading application.

In the definition of the concrete material, it was necessary to input the data of the CDP model, i.e.: dilation angle $(\Psi)$, eccentricity $(m)$, biaxial and uniaxial stress ratio $\left(\sigma_{b 0} / \sigma_{c 0}\right)$, form factor $\left(K_{c}\right)$ and viscosity $(\mu)$. For the parameters $m$, $\mathrm{K}_{\mathrm{c}}$ and $\sigma_{\mathrm{b} 0} / \sigma_{\mathrm{c} 0}$, the recommended values were used in the Abaqus application (Abaqus, 2014): $\mathrm{m}=0.1, \mathrm{Kc}=2 / 3$ and $\sigma_{\mathrm{bo}} / \sigma_{\mathrm{c} 0}=1.16$. The parameters were investigated by numerical response sensitivity analysis and values of $30 \circ$ for dilation angle and 0.0001 for viscosity were adopted. In addition, in the material definition it is necessary to add stress-strain curves and damage evolution laws, described in sections 5.1, 5.2 and 5.3.

The concrete was modeled as a solid element C3D8R, which has eight nodes and three degrees of freedom per node, translations in the main $x, y$ and $z$ directions, and reduced integration. Steel bars were modeled as the beam element, which has two nodes with six degrees of freedom per node (translations in $\mathrm{x}, \mathrm{y}$ and $\mathrm{z}$ directions and rotations in them), totally embedded into solid element (Concrete - C3D8R). 
Regarding the mesh, a previous study was developed to evaluate the influence of the finite element size on the structure response (force-displacement curve). For this mesh test, the beam was subjected to flexural monotonic load. Additionally, it was considered using rigid supports. The mesh varied between $30 \mathrm{~mm}, 50 \mathrm{~mm}, 75 \mathrm{~mm}$ and $100 \mathrm{~mm}$. Figure 14 presents the comparison between the results of the numerical models. Note that the results of the $25 \mathrm{~mm}$ and $50 \mathrm{~mm}$ meshes were very close, while for models with $75 \mathrm{~mm}$ and $100 \mathrm{~mm}$ meshes there was a slight difference in results. Due to the processing time, the $50 \mathrm{~mm}$ mesh was utilized, since this model was processed in 2 hours, while the $30 \mathrm{~mm}$ mesh model was processed in 4 hours. Figure 15 shows a beam model, steel bars and the pistons used in the test.

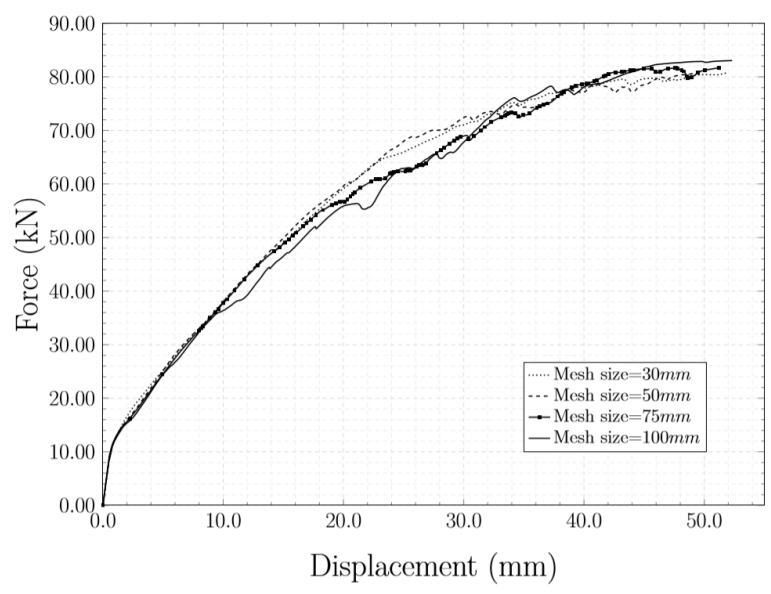

Figure 14 Convergence test
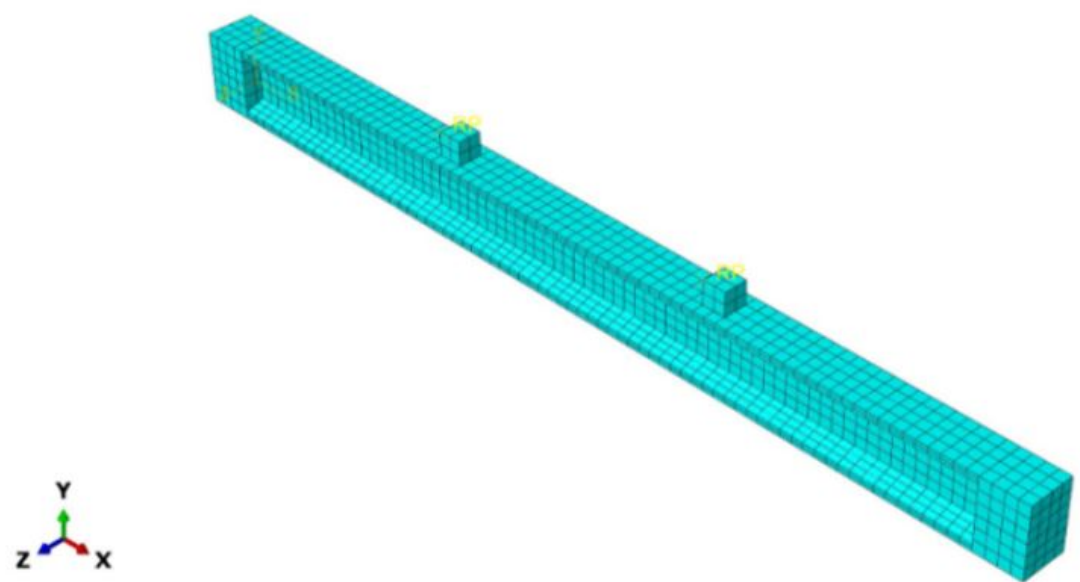

(a)

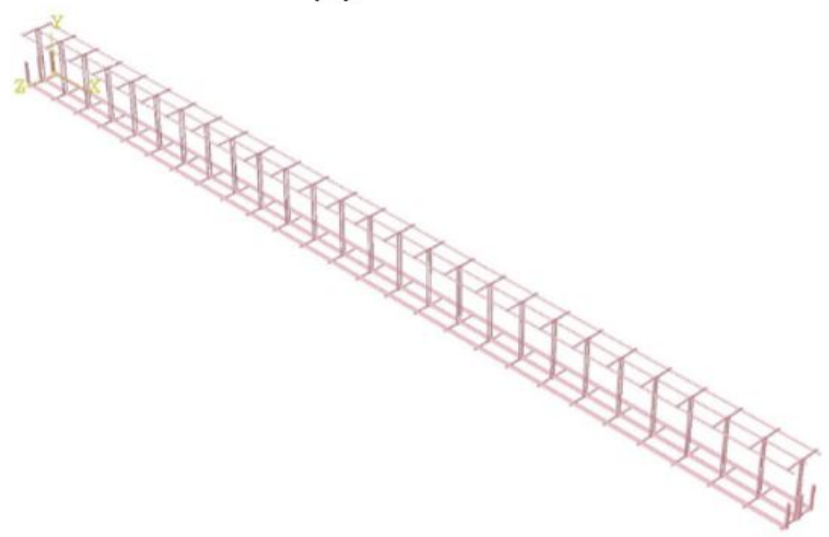<smiles>[Z]C([Y])[C]</smiles>

(b)

Figure 15 FEM model (geometries, atuactor and mesh): (a) concrete and actuator; (b) steel bars 
Regarding the support, it used a spring with 3 directions (i.e., $x, y$ and $z$ ). This boundary condition is compatible with the neoprene support. After sensitivity analysis, the spring stiffness used was $3 \mathrm{MN} / \mathrm{m}$.

Figure 16 shows the steps of loading and unloading. In step 1, the beam reached 50\% of the peak load; in step 2, the structure was unloaded; in step 3, the beam was again loaded until the peak and, finally, it was unloaded (step 4). Note that after each loading/unloading cycle, a residual displacement remains in the beam.

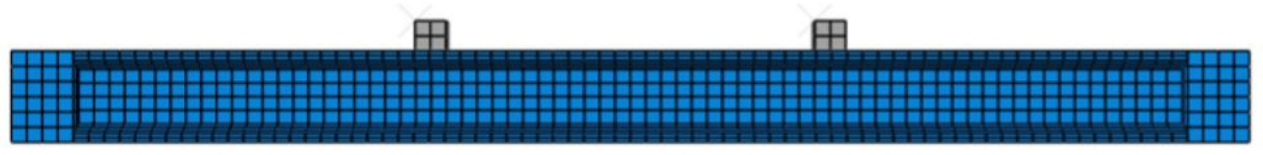

(a)

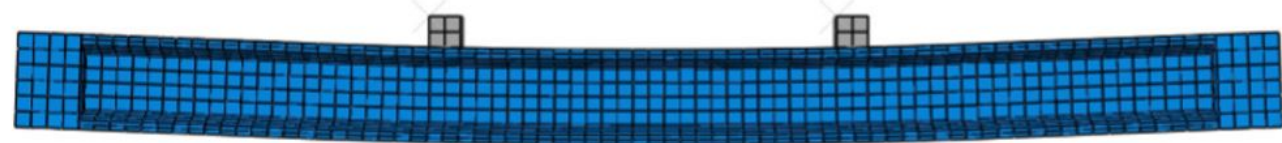

(b)

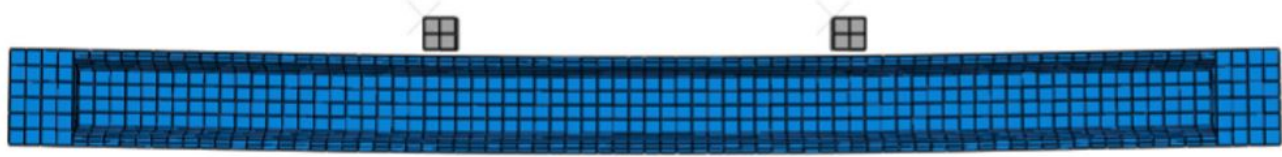

(c)

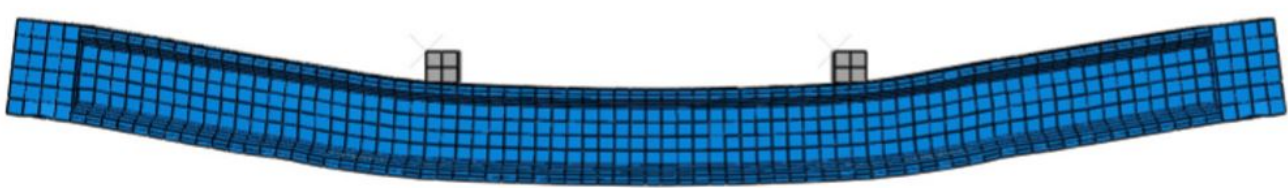

(d)

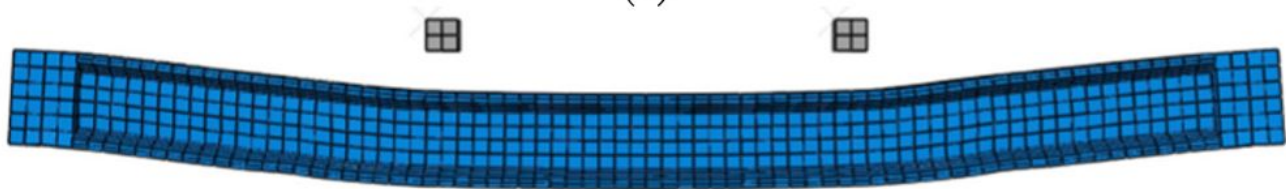

(e)

Figure 16 Load steps: (a) before the load (b) $50 \%$ of peak load (c) after the 1 st unload (d) peak load (e) after the unload

The numerical model was calibrated based on the natural frequencies used to evaluate the structural stiffness degradation as the load was applied. The calibration of the intact structure was done by the automatic updating of the finite element model, a methodology based on a genetic algorithm optimization method in Python and the finite element model elaborated in Abaqus. Parameters of interest adopted in the implementation of the genetic algorithm were population with 50 individuals, crossover rate of 0.90 , mutation rate of 0.10 , roulette method with elitism for selection of individuals. The optimization problem is defined by Eq. 18:

$\min _{E, k}\left(\max \left|\frac{f_{\exp }-f_{\text {num }}}{f_{\text {exp }}}\right| \cdot 100 \%\right)$

subject to:

$$
\begin{aligned}
& 34 \mathrm{GPa} \leq E \leq 51 \mathrm{GPa} \\
& 1 \cdot 10^{6} \mathrm{~N} / \mathrm{m} \leq k \leq 3 \cdot 10^{6} \mathrm{~N} / \mathrm{m}
\end{aligned}
$$

The optimization problem aims to reduce the difference between the natural frequencies obtained experimentally $\left(f_{\text {experimental }}\right)$ and the numerical model $\left(f_{\text {numerical }}\right)$. This objective is achieved by calibrating the elasticity modulus and the spring stiffness. 


\section{RESULTS AND DISCUSSIONS}

\subsection{Bending test}

The beam presented the expected failure mode, flexural failure mode, with several vertical cracks in the middle of the span, going up the neutral line towards the application of the force in the beam, as shown in Figure 17. Note that the distribution of cracks observed in the experimental model is also present in the numerical model.

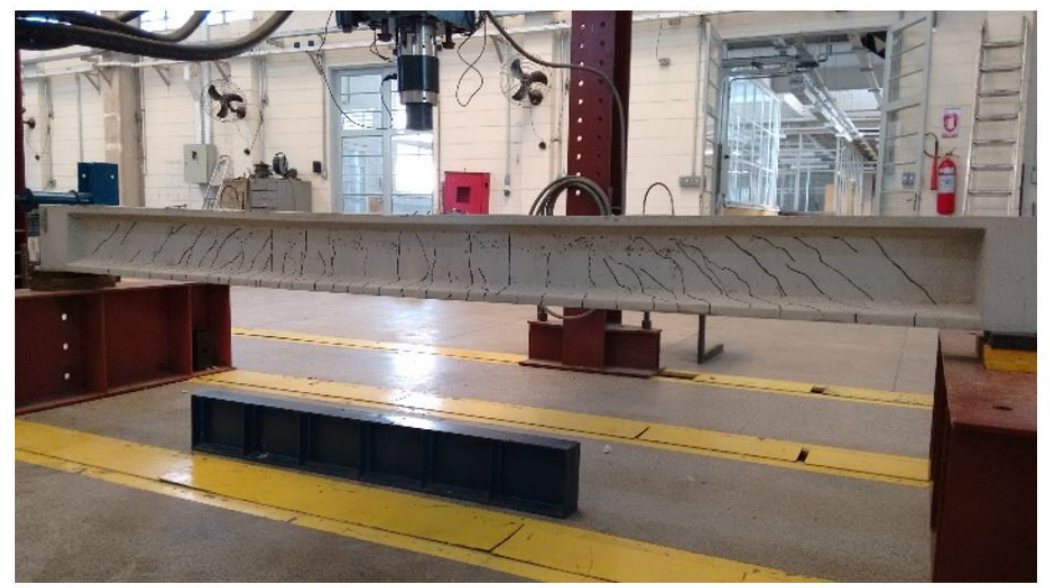

(a)
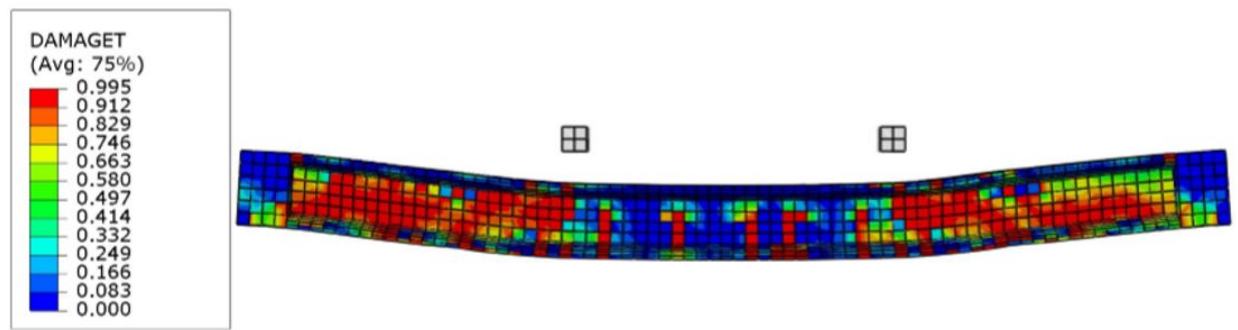

(b)

Figure 17 Beam cracking after bending test (a) experimental model (b) numerical model

The maximum strain measured by the three strain gauges placed on the longitudinal bars were $15.33 \%$, $14.82 \%$ and $13.45 \%$ (the location of the strain gauges is shown in Figure 6). Figure 18.a shows the evolution of the deformation in the reinforcement with load application. For the three bars, very similar deformations are noted, demonstrating that the beam was equally and satisfactorily distributing the stresses induced by the applied vertical loading. The maximum strain in the concrete was measured by the three strain gauges $2.84 \%$ o, $1.97 \%$ and $1.92 \%$, see Figure 18 .b. With these strain values, it is concluded that this failure mode is typical of domain 2, where the steel flows to values close to $10 \%$ and the concrete presents deformation less than $3.5 \%$, with no crushing in the compression region. In addition, the maximum strain measured by the two strain gauges placed in the stirrups was $2.05 \%$ and $1.77 \%$, as shown in Figure 18.c. These values indicate the beginning of the stirrup flow, which explains the existence of inclined cracks. 


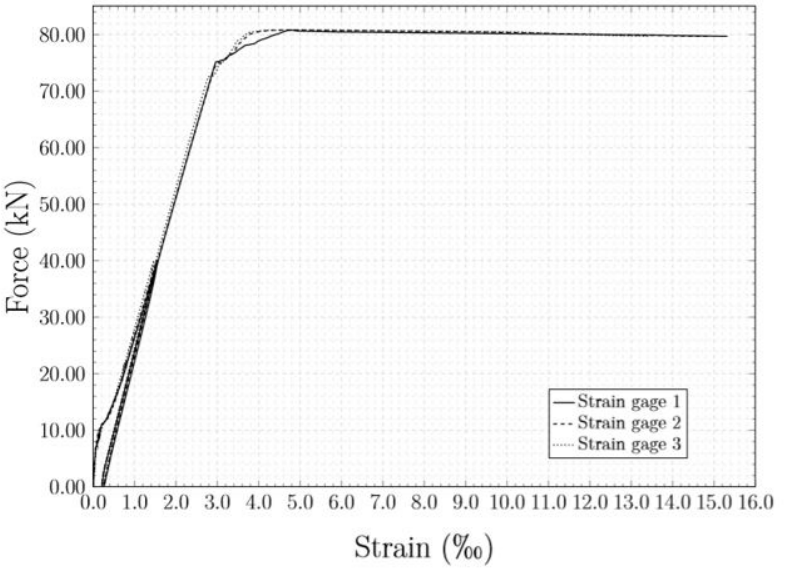

(a)

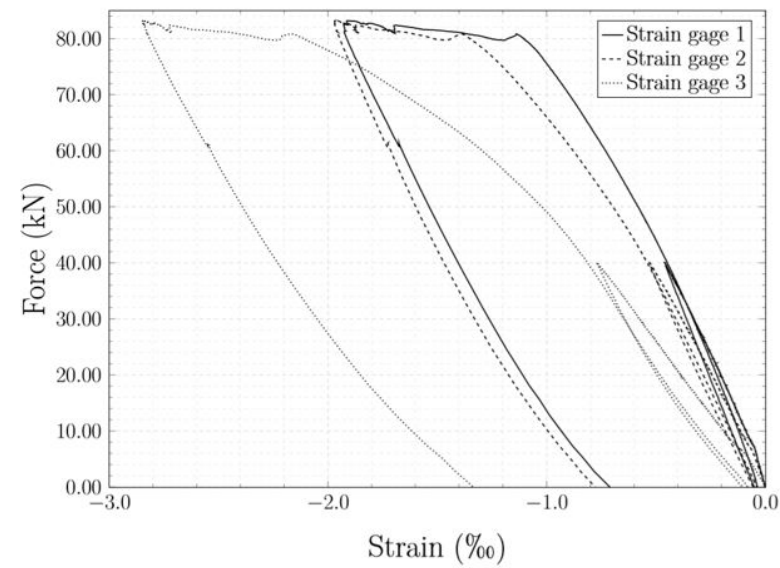

(b)

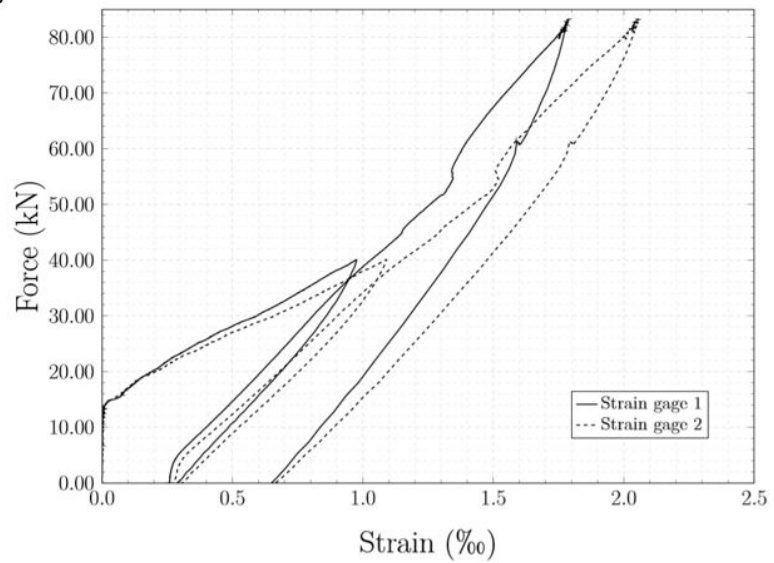

(c)

Figure 18 Deformation of (a) longitudinal bars (b) concrete (c) Stirrup

Figure 19 shows the force-displacement curve at the central span of the beam obtained by the test and the finite element models. The load applied up to $50 \%$ of the calculated maximum force, approximately $40 \mathrm{kN}$, then the beam was unloaded, which had a residual displacement, and the force was reapplied until its rupture. Note that the ultimate load was close to $80 \mathrm{kN}$, as predicted by the analytical study prior to the test. In the unload branch a reduction in the curve slope is observed, suggesting the presence of damage to the structure. To conduct a counter test, another similar sample was subject to a monotonic load, and the same force-displacement was observed, according to Fig. 19:

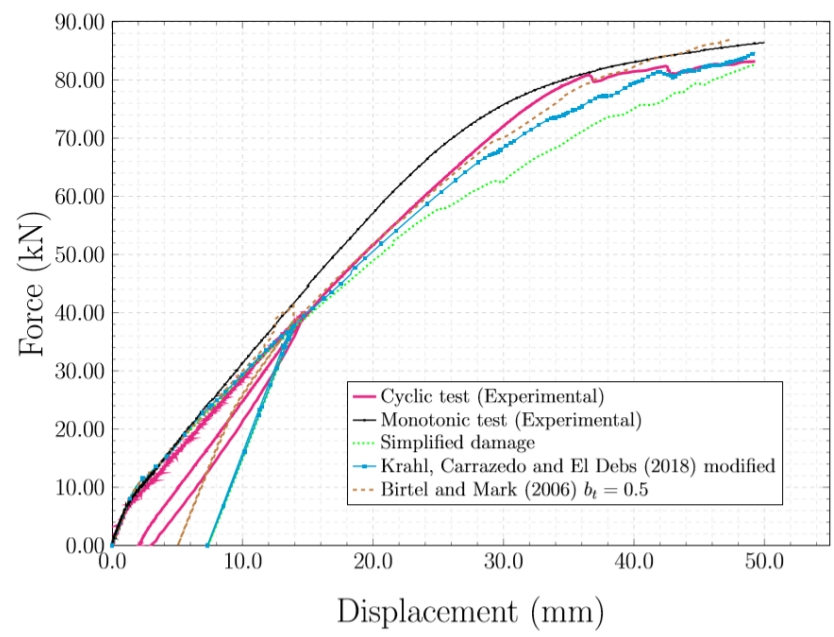

Figure 19 Bending test response 


\subsection{Dynamic test}

In order to estimate the overall damage of the tested structure, a dynamic test was performed to determine the natural frequencies of the beam, see Figure 20 . Thus, this was performed with the intact beam, after $50 \%$ of the loading had been applied and after rupture. In the three stages, one vertical and two horizontal frequencies were measured, as shown in Table 4. Figure 21 shows the signals obtained for the second horizontal frequency. It is noted that the frequency is reduced with the increase of damage due to mechanical stress. Natural frequency correlates to stiffness and mass. As damage is a degradation of stiffness, a drop in frequency was expected as the flexure test progressed.

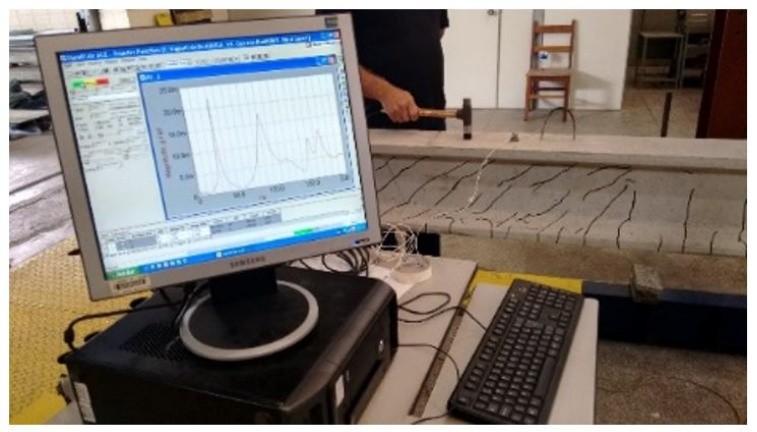

(a)

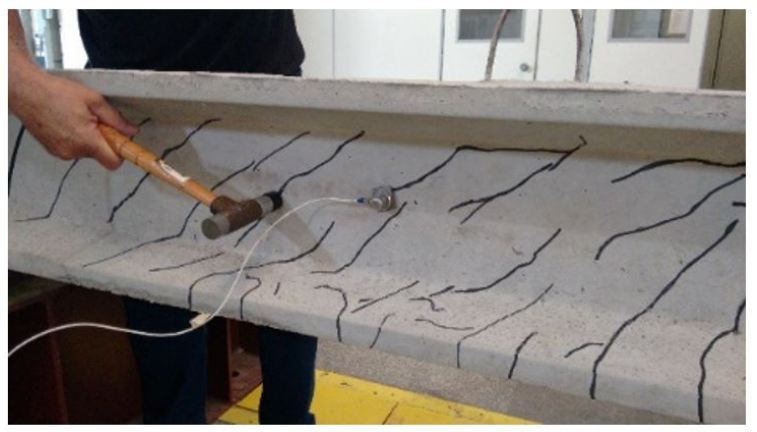

(b)

Figure 20 Dynamic test to obtain natural frequencies (a) vertical (b) horizontal

Table 4 Natural frequencies obtained by dynamic test

\begin{tabular}{|c|c|c|c|}
\hline \multirow{3}{*}{ Stage } & \multicolumn{3}{|c|}{ Natural Frequencies $(\mathrm{Hz})$} \\
\hline & \multirow{2}{*}{$\frac{\text { Vertical loading }}{1 \underline{\underline{a}}}$} & \multicolumn{2}{|c|}{ Horizontal loading } \\
\hline & & $1 \underline{a}$ & 2 \\
\hline Before the test & 99.4 & 41.3 & 85.0 \\
\hline $\mathrm{F}=40 \mathrm{kN}$ & 95.0 & 38.8 & 79.4 \\
\hline Final & 85.6 & 34.4 & 67.5 \\
\hline
\end{tabular}

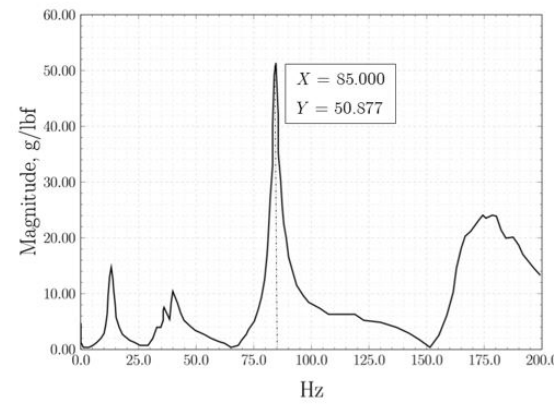

(a)

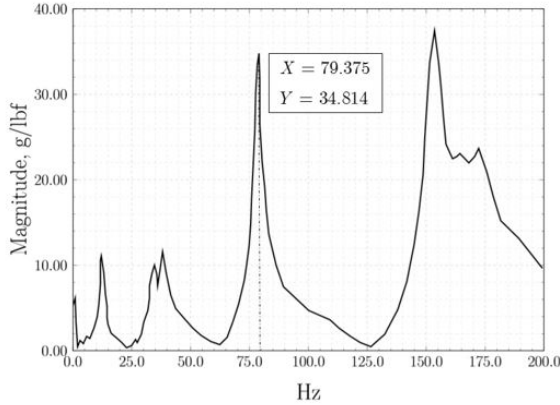

(b)

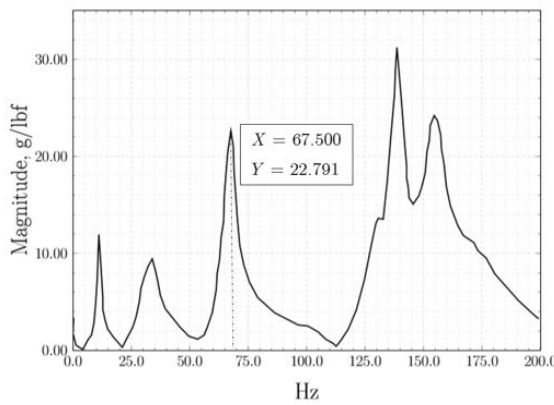

(c)

Figure 21 Signals obtained by the dynamic test (a) before the static test (b) after 50\% load was applied (c) after rupture of the beam

The numerical model was calibrated based on the experimental natural frequencies. Figure 22 illustrates the evolution of the genetic algorithm, that is the reduction of the objective function with the generation. The stopping criteria was defined by the number of iterations and the limit was 200 generations. The calibrated elasticity modulus was 40.6 GPa and the spring stiffness was $1.10^{6} \mathrm{~N} / \mathrm{m}$. The results were consistent, since the dynamic modulus of elasticity was approximately $20 \%$ greater than the static modulus of elasticity and the spring stiffness was lower in the dynamic test compared to the static test. It is noteworthy that the spring of the numerical model simulates the neoprene support. 


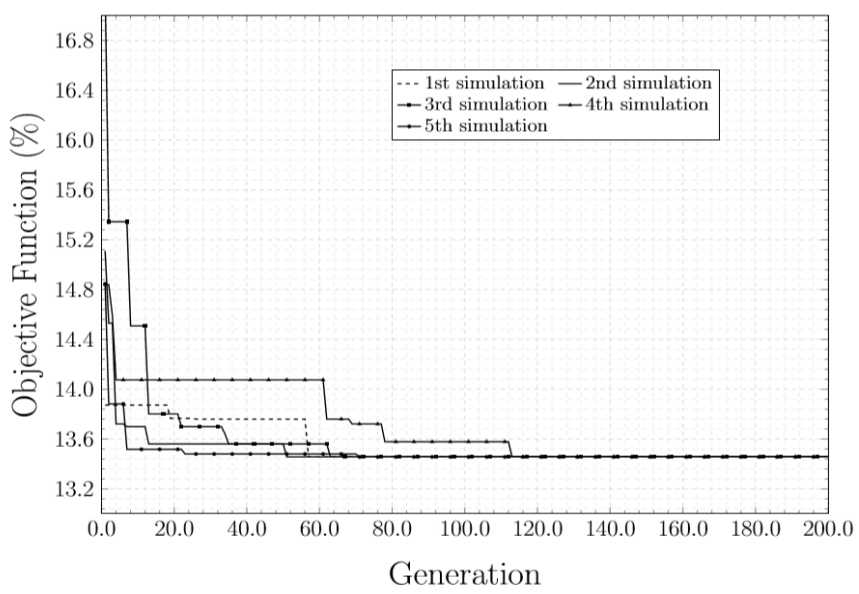

Figure 22 Evolution of the genetic algorithm

The calibration of the numerical model, considering the application of $50 \%$ and $100 \%$ of the load, was done by the total enumeration method, considering that the spring stiffness adopted was the same as the intact structure and only the elasticity modulus was calibrated. Therefore, elasticity modulus values ranging from $20 \mathrm{GPa}$ to $40 \mathrm{GPa}$ were evaluated. Figure 23 shows the value of the objective function with the modulus variation. From Figure 23 , it is observed that in the first loading stage the $33 \mathrm{GPa}$ value resulted in the lowest objective function value and in the second stage the value of $21.4 \mathrm{GPa}$ better calibrated the model. Table 5 presents the natural frequencies of the calibrated numerical model as well as the calibrated elasticity modulus.

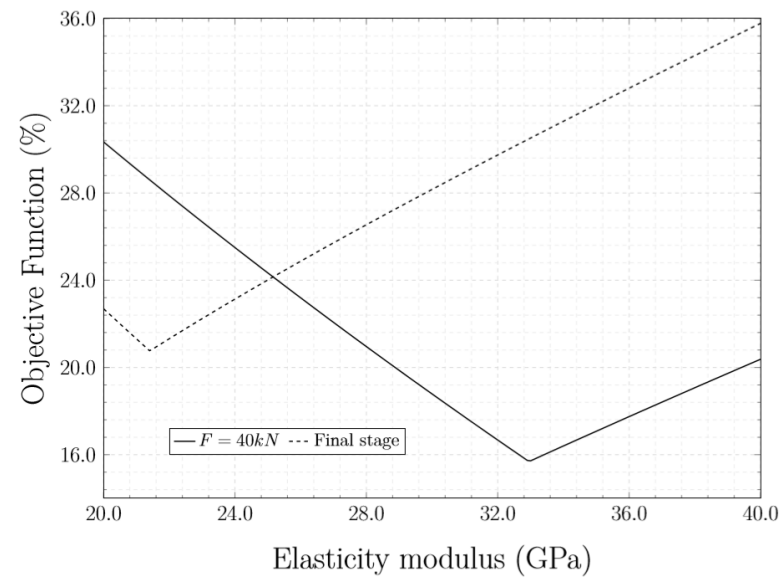

Figure 23 Calibration of elasticity modulus

Table 5 Natural frequencies obtained by dynamic test simulation

\begin{tabular}{ccccc}
\hline & \multicolumn{3}{c}{ Natural Frequencies (Hz) } & \multirow{2}{*}{ Elasticity modulus (GPa) } \\
\cline { 2 - 4 } Stage & Vertical loading & \multicolumn{2}{c}{ Horizontal loading } & 2 a \\
\cline { 2 - 4 } & 1 a & 46.9 & 73.6 & 40.6 \\
\hline Before the test & 87.3 & 44.9 & 68.2 & 33.0 \\
F $=40 \mathrm{kN}$ & 80.1 & 41.5 & 58.9 & 21.4 \\
Final & 67.8 & & \\
\hline
\end{tabular}

\subsection{Damage estimates}

An estimate of the overall damage to the structure can be made by correlating the frequency of intact and damaged structures using Eq. 19 (DiPasquale et al., 1990): 


$$
d=1-\frac{f_{\text {damaged }}^{2}}{f_{\text {undamaged }}^{2}}
$$

By the natural frequencies obtained experimentally shown in Table 4, it is estimated that the overall damage after the first loading cycle was 0.11 and after the beam rupture was 0.31 . By the natural frequencies obtained by the calibrated numerical model, presented in Table 5, it is estimated that the overall damage after the first loading cycle was 0.13 and after beam rupture was 0.32 . It is noted that the estimates obtained by the numerical and experimental models are relatively close.

Another estimate of damage is given by the relationship between the elasticity modulus of the damaged structure and the intact structure, as presented in Eq. 20.

$$
d=1-\frac{E_{\text {damaged }}}{E_{\text {undamaged }}}
$$

From Eq. 20 it is possible to estimate the numerical model damage based on the elasticity modulus calibrated at each loading stage. Using the data presented in Table 5, an overall damage estimate of 0.19 and 0.47 is obtained after half of the load has been applied and after failure, respectively. From this equation, the damage estimate is $46 \%$ higher than the damage estimate based on natural frequencies in both stages.

Another methodology used to estimate the damage was to evaluate the average damage of the model in finite element analysis. The first loading stage obtained a damage of 0.15 and the second stage obtained a damage of 0.39 . It is observed that the values found are within the limits obtained by the previous methodologies.

\section{CONCLUSIONS}

This paper demonstrated the numerical-experimental validation and calibration of a reinforced I-beam, subjected to cyclic loading in a 4-point test. Sections 1 and 2 cover the basic concepts of the Concrete Damaged Plasticity model. The objectives are reported in section 3. Subsequently, section 4 presents the characterization of the materials of this beam and section 5 describes the aspects inherent to the I-beam numerical modeling. The experimental and numerical results are presented in section 6 . Therefore, the main points can be highlighted as follows:

- When loading was considered monotonic, all damage laws were successful in predicting the beam displacement force diagram. The simplified damage model presented a maximum load $1.27 \%$ lower than the experimental one, while the Krahl, Carrazedo and El Debs (2018) and Birtel and Mark (2006) models resulted in a maximum load 0.89\% and $8.56 \%$ higher than the experimental model, respectively;

- However, when we considered the loading step, the Birtel damage law $\left(b_{t}=0.5\right)$ showed the most realistic results, where the experimental residual displacement observed was $2.43 \mathrm{~mm}$ and the Birtel and Mark (2006) model presented a deflection of $5.04 \mathrm{~mm}$. The simplified model and the model proposed by Krahl, Carrazedo and El Debs (2018) presented $7.36 \mathrm{~mm}$ and $7.31 \mathrm{~mm}$ deflections, respectively. This behavior is explained by the proportion assumed between the plastic and damage strains, where the Birtel model with $b_{t}=0.5$ is the best match to compute these strains correctly;

- $\quad$ Additionally, it should be noted that the use of the values prescribed by Birtel and Mark (2006), i.e., $b_{t}=0.1$, make the computational processing of the numerical model unfeasible;

- $\quad$ Although the Krahl, Carrazedo and El Debs (2018) model is originally proposed for ultra high performance fiber reinforced concrete, it has proven satisfactory for monotonic representation of the load;

- The Carreira and Chu (1985) constitutive laws and the Model Code (COMITÉ EURO-INTERNACIONAL DU BÉTON, 2010) were satisfactory for the simulation of the I-beam, and can be used successfully for concrete produced in Brazil;

- $\quad$ The model developed in the present article successfully correlated the tensile damage index with the cracking pattern observed in the experimental beam. Therefore, the methodology described in this article may be used as an aid to predict the failure mode of the structural element;

- The estimate of damage was done by the ratio of the natural frequencies of the structure in the intact and damaged stages; such an estimate was very close in experimental models and numerically calibrated; 
- The damage estimate based on the global modulus of elasticity value of the finite element calibrated model was approximately $46 \%$ higher than the estimate obtained by natural frequencies. Thus, the authors suggest that the applied methodologies can be used as upper and lower limits of the tensile damage variable.

- $\quad$ For future research, the authors suggest the development of the relation between crack width model and CDP damage parameters (i.e., $\mathrm{dt}$ and $\mathrm{dc}$ ).

\section{Acknowledgements}

The authors gratefully acknowledge the financial support provided by the National Council for Scientific and Technological Development (CNPq), process number 140882/2019-7.

Author's Contribuitions: Conceptualization, PO Ribeiro, GMS Gidrão, LV Vareda, R Carrazedo, M Malite; Methodology, PO Ribeiro, GMS Gidrão, LV Vareda, R Carrazedo, M Malite; Investigation, PO Ribeiro, GMS Gidrão, LV Vareda, R Carrazedo, M Malite; Writing - original draft, PO Ribeiro, GMS Gidrão; Writing - review \& editing, PO Ribeiro, GMS Gidrão, LV Vareda, R Carrazedo, M Malite; Supervision, R Carrazedo, M Malite.

Editor: Marcílio Alves

\section{References}

Abaqus, V. 6.14 (2014). Documentation. Dassault Systemes Simulia Corporation, v. 651.

Birtel, V., Mark, P. (2006). Parameterised finite element modelling of RC beam shear failure. In ABAQUS users' conference ( $p p$. 95-108).

Carreira, D. J., Chu, K. H (1985). Stress-strain relationship for plain concrete in compression. ACI Journal, v. 82(6), n. 6, p. 797804.

Chen, L., Graybeal, B. A. (2011). Modeling structural performance of ultrahigh performance concrete I-girders. Journal of Bridge Engineering, 17(5), 754-764.

COMITÉ EURO-INTERNACIONAL DU BÉTON (2010). CEB-FIB Model Code 2010, London.

DiPasquale, E., Ju, J. W., Askar, A., Çakmak, A. S. (1990). Relation between global damage indices and local stiffness degradation. Journal of Structural Engineering, 116(5), 1440-1456.

Genikomsou, A. S., Polak, M. A (2015). Finite element analysis of punching shear of concrete slabs using damaged plasticity model in ABAQUS. Engineering Structures, v. 98, p. 38-48.

Graybeal, B. A. (2008). Flexural behavior of an ultrahigh-performance concrete l-girder. Journal of Bridge Engineering, 13(6), 602-610.

Jankowiak, T., Lodygowski, T. (2005). Identification of parameters of concrete damage plasticity constitutive model. Foundations of civil and environmental engineering, v. 6, n. 1, p. 53-69.

Johnson, S. (2006). Comparison of Nonlinear Finite Element Modeling Tools for Structural Concrete. [s.I.] University of Illinois.

Kmiecik, P., Kaminski, M. (2011). Modelling of reinforced concrete structures and composite structures with concrete strength degradation taken into consideration. Archives of civil and mechanical engineering, v. 11, n. 3, p. 623-636.

Krahl, P. A., Carrazedo, R., El Debs, M. K. (2018). Mechanical damage evolution in UHPFRC: experimental and numerical investigation. Engineering Structures, 170, 63-77.

Lee, J. H., Fenves, G. L (1998). Plastic-damage model for cyclic loading of concrete structures. J. Eng. Mech. (ASCE), v. 124, n. 8, p. 892-900.

Lubliner, J., Oliver, J., Oller, S., Oñate, E. (1989). A plastic-damage model for concrete. International Journal of solids and structures, 25(3), 299-326. 
Michal, S., Andrzej, W. (2015). Calibration of the CDP model parameters in Abaqus. In: The 2015 World Congress on Advanced in Structural Engineering and Mechanics.

Pavlović, M., Marković, Z., Veljković, M., Buđevac, D. (2013). Bolted shear connectors vs. headed studs behaviour in push-out tests. Journal of Constructional Steel Research, v. 88, p. 134-149.

Singh, M., Sheikh, A. H., Ali, M. M., Visintin, P., Griffith, M. C. (2017). Experimental and numerical study of the flexural behaviour of ultra-high performance fibre reinforced concrete beams. Construction and Building Materials, 138, 12-25.

Sümer, Y., Aktaş, M. (2015). Defining parameters for concrete damage plasticity model. Challenge Journal of Structural Mechanics, 1(3), 149-155.

Tao, Y., Chen, J. F. (2014). Concrete damage plasticity model for modeling FRP-to-concrete bond behavior. Journal of Composites for Construction, 19(1), 04014026.

Wahalathantri, B. L., Thambiratnam, D. P., Chan, T. H. T., \& Fawzia, S. (2011). A material model for flexural crack simulation in reinforced concrete elements using ABAQUS. In Proceedings of the first international conference on engineering, designing and developing the built environment for sustainable wellbeing (pp. 260-264). Queensland University of Technology. 